\title{
FAKTOR-FAKTOR YANG BERHUBUNGAN DENGAN PELAKSANAAN THAHARAH (PERSONAL HYGENE) SELAMA MENSTRUASI PADA REMAJA PUTRI DI PASANTREN BABUN NAJAH BANDA ACEH
}

\author{
FACTORS RELATED TO IMPLEMENTATION OF THAHARAH \\ (PERSONALHYGENE) DURING MENSTRUATION ADOLESCENT IN \\ PASANTREN BABUN NAJAH BANDA ACEH
}

\author{
Rahma Dalila Fitri' ${ }^{1}$, Eulisa Fajriana ${ }^{2}$ \\ Akbid Muhammadiyah Banda Aceh, Jalan Harapan No. 14, Punge Blang Cut Banda Aceh, 23234. Indonesia \\ Korespondensi Penulis: ${ }^{1}$ rahmadalila05@gmail.com; ${ }^{2}$ lismunas@gmail.com
}

\begin{abstract}
Abstrak
Kebersihan selama menstruasi sangat penting untuk diketahui, dan dilaksanaka dikarenakan efek yang bisa ditimbulkan dari hygene yang buruk selama haid iritasi vagina $64,1 \%$, penyakit Infeksi Saluran Kencing (ISK) sebanyak 75\% keputihan sebanyak 60\%. Metode Penelitian yang digunakan adalah penelitian kuantitatif dengan pendekatan cross sectional. Populasi dan Sampel pada penelitian ini berjumlah 318 orang. Hasil Penelitian menunjukkan pengetahuan berhubungan dengan pelaksanaan thaharah $\mathrm{p}$ value $(0,038)$, sikap dengan pelaksanaan thaharah $\mathrm{p}$ value $(0,04)$, usia menarche dengan pelaksanaan thaharah $\mathrm{p}$ value $(0,01)$, pendidikan dengan pelaksanaan thaharah $\mathrm{p}$ value $(0,02)$ dan dukungan keluarga dengan pelaksanaan thaharah $p$ value $(0,02)$.
\end{abstract}

Kata Kunci : Faktor, Pelaksanaan, Thaharah (Personal Hygiene), Menstruasi, Remaja

\begin{abstract}
Personal higyene during of menstruation important for women because side effect bad hygiene is 64,1\% vagina irritation, urinary tract infections (UTI) as much $75 \%$ vaginal discharge 60\%, and cervical cancer as 15.000 women annually.. This research using cross sectional approach for quantitative research. Population and sample for this research were 318 officer. The results show knowledge with the implementation of thaharah $p$ value (0.038), attitudes with the implementation of thaharah $p$ value (0.04), the age of menarche of thaharah $p$ value (0.01), education with implementation of thaharah $p$ value (0.02) and family support implementing thaharah p value (0.02).
\end{abstract}

Keywords : Factor, Implementation, Thaharah (personal hygiene), Menstruation, adolescent 
Journal of Healthcare Technology and Medicine Vol. 5 No. 2 Oktober 2019

Universitas Ubudiyah Indonesia

e-ISSN : 2615-109X

\section{PENDAHULUAN}

Perubahan fisik, dan psikologis dari anak menjadi dewasa yang ditandai dengan pematangan organ reproduksi, psikologis, psikososial dan seksual serta keluarnya darah haid pada wanita dan mimpi basah pada pria (Eswi, dkk 2012). Haid merupakan pelepasan dinding rahim yang disertai perdarahan dan terjadi secara berulang setiap bulan. Menstruasi yang pertama kali di sebut menarche paling sering terjadi pada usia 11 tahun tetapi bisa juga terjadi pada usia 8 tahun atau 16 tahun. Menstruasi merupakan pertanda masa reproduktif pada kehidupan seorang wanita (Manan, 2011)

Thaharah menurut bahasa berarti bersuci, sedangkan menurut syara' atau istilah adalah aktivitas-aktivitas tertentu untuk mensucikan atau membersihkan diri, pakaian, tempat dan benda-benda lain dari najis dan hadas menurut cara-cara yang ditentukan oleh syariat islam (Hidayat, 2011). Sedangkan Personal Hygiene merupakan suatu tindakan untuk memelihara kebersihan dan kesehatan diri seseorang untuk kesejahteraan fisik dan psikis (Depkes, 2012). Hasil penelitian yang dilakukan Fitriyah, dkk (2013) pada remaja yang berpengetahuan kurang tentang riwayat kesehatan reproduksi mengalami keputihan yang abnormal 35,7\%.

. Berdasarkan hasil survey yang dilakukan WHO pada wanita berusia 10-14 tahun bermasalah dengan kesehatan reproduksinya. Permasalahan terjadi karena pengetahuan yang kurang tentang perawatan organ reproduksi, yang dapat menimbulkan penyakit ISK 30\%, keputihan 50\% dan kanker servik 470.000 wanita setiap tahunnya (Priyitno,2014).

Berdasarkan data yang di peroleh dari Badan Pusat Statistik Provinsi Aceh tahun 2016 jumlah penduduk sebanyak 5.096.248, sedangkan jumlah remaja putri usia 10-19 tahun sebanyak 5.096.248 jiwa (Profil Dinas Kesehatan Provinsi Aceh, 2016).

Tujuan penelitian ini adalah untuk mengetahui Faktor-faktor yang berhubungan dengan pelaksanaan thaharah (personal hygine) selama menstruasi pada remaja putri di Pasantren Babun Najah Banda Aceh. Tujuan Khusus a) Mengetahui pelaksanaan thaharah selama menstruasi pada remaja putri. b) Mengetahui hubungan antara pengetahuan dengan pelaksanaan thaharah selama menstruasi pada remaja putri. c) Mengetahui hubungan antara sikap dengan pelaksanaan thaharah selama menstruasi pada remaja putri. d) Mengetahui hubungan antara Usia Menarche dengan pelaksanaan Thaharah selama menstruasi pada remaja putri. e) Mengetahui hubungan antara tingkat pendidikan ibu dengan pelaksanaan thaharah selama menstruasi pada remaja putri d) Mengetahui hubungan antara dukungan keluarga dengan pelaksanaan thaharah selama menstruasi pada remaja putri. Manfaat penelitian ini sebagai sumber bagaimanakah pelaksanaan thaharah yang dilakukan remaja putri di Pasantren Babun Najah Banda Aceh. 
Journal of Healthcare Technology and Medicine Vol. 5 No. 2 Oktober 2019

Universitas Ubudiyah Indonesia

e-ISSN : 2615-109X

\section{METODE PENELITIAN}

Desain penelitian yang digunakan adalah penelitian kuantitatif dengan pendekatan cross sectional adalah suatu penelitian untuk mempelajari dinamika korelasi antara faktor-faktor dengan efek, dengan cara pendekatan,observasi atau pengumpulan data sekaligus pada suatu saat (point time approach).

Penelitian dilakukan tanggal 18 Juli 2019 pada 318 orang remaja putri di Pasantren Babun Najah Banda Aceh. Metode pengumpulan data penelitian ini dengan menggunakan cheklist dan kuesioner yang dibagi pada responden dan responden mengisi checklist dan kuesioner yang telah dibagikan. Setelah data terkumpul, dilakukan editing untuk mengetahui kelengkapan data, coding untuk memudahkan tabulasi data dana analisis data menggunakan SPSS 16. Analisa data yang digunakan univariat dan bivariat untuk menganalisis variabelvariabel penelitian guna menguji hipotesis penelitian serta untuk melihat gambaran hasil penelitian. Analisa data dilakukan dengan menggunakan SPSS 16 untuk menganalisa data secara deskriptif dan analitik, sedangkan Teknik analisis yang digunakan adalah Chi square untuk menganalisis variabel penelitian.

\section{HASIL DAN PEMBAHASAN}

\section{Hasil}

Berdasarkan hasil penelitian yang dilakukan pada tanggal 18 Juli 2019 tentang Faktor-

Faktor Yang Berhubungan Dengan Pelaksanaan Thaharah (Personal Hygiene) Selama Menstruasi Pada Remaja Putri di Pasantren Babun Najah Banda Aceh. Kuesioner dibagikan kepada 318 orang remaja putri yang sudah menstruasi dan terdaftar sebagai siswi di Pasantren Babun Najah Banda Aceh. Dari penelitian yang telah dilakukan diperoleh hasil sebagai berikut: 


\section{a. Analisa Univariat}

1) Umur

Tabel 4.1

Distribusi Frekuensi Umur Remaja Putri

di Pasantren Babun Najah Banda Aceh

\begin{tabular}{|c|c|c|c|}
\hline No & Umur & f & $\%$ \\
\hline 1 & Remaja Awal 10-14 & 154 & 48.4 \\
\hline 2 & Remaja Tengah 14-17 & 161 & 50.6 \\
\hline 3 & Remaja Akhir 17-21 & 3 & 1 \\
\hline & Total & 318 & 100 \\
\hline
\end{tabular}

Sumber : Data Primer (Diolah Tahun 2019)

Berdasarkan tabel 4.1 dapat diketahui bahwa dari 318 responden adalah remaja tengah yang berusia 14-17 tahun 161 responden 50,6\%.

\section{2) Sumber Informasi}

\section{Tabel 4.2}

Distribusi Frekuensi Sumber Informasi Remaja Putri Tentang

Pelaksanaan Thaharah (Personal Hygiene) Selama Menstruasi di Pasantren Babun Najah Banda Aceh

\begin{tabular}{|c|c|c|c|}
\hline No & Sumber Informasi & f & \% \\
\hline & Orang Tua & 248 & 77,9 \\
\hline & Belajar & 114 & 35,8 \\
\hline & Fiqih & 120 & 37,7 \\
\hline & Teman & 52 & 16,3 \\
\hline & Tenaga Kesehatan & 38 & 11,9 \\
\hline & Saudara & 42 & 13,2 \\
\hline & Lainnya & 19 & 5,9 \\
\hline
\end{tabular}

Sumber : Data Primer (Diolah Tahun 2019)

Berdasarkan tabel 4.2 diketahui bahwa dari 318 responden yang mendapatkan informasi tentang pelaksanaan thaharah dari orang tua sebesar 248 responden $(77,9 \%)$.

\section{3) Pelaksanaan Thaharah}

Tabel 4.3

Distribusi Frekuensi Pelaksanaan Thaharah (Personal Hygiene)

Selama Menstruasi Pada Remaja Putri di

Pasantren Babun Najah Banda Aceh

\begin{tabular}{|c|c|c|c|}
\hline No & Pelaksanaan Thaharah & f & \% \\
\hline 1 & Baik & 149 & 47 \\
\hline 2 & Kurang & 169 & 53 \\
\hline & Jumlah Total & 318 & 100 \\
\hline
\end{tabular}

Sumber : Data Primer (Diolah Tahun 2019) 
Journal of Healthcare Technology and Medicine Vol. 5 No. 2 Oktober 2019

Universitas Ubudiyah Indonesia

e-ISSN : 2615-109X

Berdasarkan tabel 4.3 diketahui bahwa dari 318 responden yang Pelaksanaan

Thaharah (Personal Hygiene) Selama Menstruasi Pada Remaja Putri di Pasantren Babun

Najah Banda Aceh berada pada kategori kurang 169 (53\%).

\section{4) Pengetahuan}

Tabel 4.4

Distribusi Frekuensi Pengetahuan Remaja Putri Tentang Pelaksanaan Thaharah (Personal Hygiene) Selama Menstruasi di Pasantren Babun Najah Banda Aceh

\begin{tabular}{|c|c|c|c|}
\hline No & Pengetahuan & f & \% \\
\hline 1 & Baik & 90 & 28,3 \\
\hline 2 & Kurang & 228 & 71,7 \\
\hline & Jumlah Total & 318 & 100 \\
\hline
\end{tabular}

Sumber : Data Primer (Diolah Tahun 2019)

Berdasarkan tabel 4.4 diketahui dari 318 responden bahwa pengetahuan Remaja Putri Tentang Pelaksanaan Thaharah (Personal Hygiene) Selama Menstruasi di Pasantren Babun Najah Banda Aceh berada pada kategori kurang 228 (71,7\%).

5) Sikap

Tabel 4.5

Distribusi Frekuensi Sikap Remaja Putri Tentang Pelaksanaan Thaharah (Personal Hygiene) Selama Menstruasi di Pasantren Babun Najah Banda Aceh

\begin{tabular}{|c|c|c|c|}
\hline No & Sikap & f & $\%$ \\
\hline 1 & Positif & 211 & 66,4 \\
\hline 2 & Negatif & 107 & 33,6 \\
\hline & Jumlah Total & 318 & 100 \\
\hline
\end{tabular}

Sumber : Data Primer (Diolah Tahun 2019)

Berdasarkan tabel 4.5 diketahui bahwa dari 318 responden Remaja Putri Tentang Pelaksanaan Thaharah (Personal Hygiene) Selama Menstruasi di Pasantren Babun Najah Banda Aceh berada pada kategori sikap negatif 211 (66,4\%).

6) Usia Menarche 
Tabel 4.6

Distribusi Frekuensi Usia Menarche Remaja Putri di Pasantren Babun Najah Banda Aceh

\begin{tabular}{|c|c|c|c|}
\hline No & Umur & f & \% \\
\hline & $<10$ tahun & 18 & 2 \\
\hline & 210 tahun & 300 & 98 \\
\hline & Total & 318 & 100 \\
\hline
\end{tabular}

Sumber : Data Primer (Diolah Tahun 2019)

Berdasarkan tabel 4.6 diketahui bahwa dari 318 responden Remaja Putri di Pasantren Babun Najah Banda Aceh, yang usia menarche $\geq 10$ tahun sebanyak 300 responden (98\%).

7) Pendidikan Ibu

Tabel 4.7

Distribusi Frekuensi PendidikanIbu Remaja Putri di Pasantren Babun Najah Banda Aceh

\begin{tabular}{|c|c|c|c|}
\hline No & Pendidikan & $\mathbf{f}$ & $\%$ \\
\hline 1 & Dasar (SD, SLTP) & 64 & 20.1 \\
\hline 2 & Menengah (SLTA) & 139 & 43.7 \\
\hline 3 & Tinggi (Diploma sederajat) & 115 & 36.1 \\
\hline & Total & 318 & 100 \\
\hline
\end{tabular}

Sumber : Data Primer (Diolah Tahun 2019)

Berdasarkan tabel 4.7 diketahui bahwa dari 318 responden remaja putri di Pasantren Babun Najah Banda Aceh yang pendidikan Ibu berada kategori Menengah sebanyak 139 $(43,7 \%)$.

8) Dukungan Keluarga

Tabel 4.8

Distribusi Frekuensi Dukungan Keluarga Tentang Pelaksanaan Thaharah(Personal Hygiene) Selama Menstruasi Pada Remaja Putri di Pasantren Babun Najah Banda Aceh

\begin{tabular}{|c|c|c|c|}
\hline No & Dukungan Keluarga & f & \% \\
\hline 1 & Mendukung & 225 & 70.8 \\
\hline 2 & Tidak Mendukung & 93 & 29,2 \\
\hline & Jumlah Total & 318 & 100 \\
\hline
\end{tabular}

Sumber : Data Primer (Diolah Tahun 2019)

Berdasarkan tabel 4.8 diketahui bahwa dari 318 responden remaja putri di Pasantren Babun Najah Banda Aceh yang mendapatkan dukungan keluarga sebanyak 225(70,8\%).

\section{b. Analisa Bivariat}

1) Hubungan Pengetahuan dengan Pelaksanaan Thaharah

Tabel 4.9

Hubungan Pengetahuan dengan Pelaksanaan Thaharah Selama Menstruasi 
Journal of Healthcare Technology and Medicine Vol. 5 No. 2 Oktober 2019

Universitas Ubudiyah Indonesia

e-ISSN : 2615-109X

Pada Remaja Putri di Pasantren Babun Najah Banda Aceh

\begin{tabular}{|l|c|c|c|c|c|c|c|}
\hline \multirow{2}{*}{ Thaharah } & \multicolumn{4}{|c|}{ Pengetahuan } & \multicolumn{2}{c|}{ Total } & \multirow{2}{*}{$\mathrm{p}$} \\
\cline { 2 - 7 } & Tinggi & \% & Rendah & \% & n & \% & \\
\hline Baik & 51 & 34,2 & 98 & 65,8 & 149 & 100 & 0.038 \\
\hline Kurang & 39 & 23,1 & 138 & 76,9 & 169 & 100 & \\
\hline
\end{tabular}

Sumber : Data Primer (Diolah Tahun 2019)

Berdasarkan tabel 4.9 menunjukkan bahwa dari 318 orang responden yang berpengetahuan rendah dan pelaksanaan thaharah kurang berjumlah 138 responden (76,9\%). Berdasarkan hasil uji Chi-Square diketahui $\mathrm{p}$ value $=0,038$ dimana 0,038<dari 0,05 maka terdapat hubungan antara Pengetahuan dengan pelaksanaan Thaharah pada remaja putri di Pasantren Babun Najah Banda Aceh.

2) Hubungan Sikap dengan Pelaksanaan Thaharah

Tabel 4.10

Hubungan Sikap dengan Pelaksanaan Thaharah Selama Menstruasi Pada Remaja Putri di Pasantren Babun Najah Banda Aceh

\begin{tabular}{|l|c|c|c|c|c|c|c|}
\hline \multirow{2}{*}{ Thaharah } & \multicolumn{4}{|c|}{ Sikap } & \multicolumn{2}{c|}{ Total } & \multirow{2}{*}{$\mathrm{p}$} \\
\cline { 2 - 8 } & Positif & \% & Negatif & \% & n & \% & \\
\hline Baik & 108 & 72.5 & 41 & 27.5 & 149 & 100 & \multirow{2}{*}{0.04} \\
\hline Kurang & 103 & 60.9 & 66 & 39.1 & 169 & 100 & \\
\hline
\end{tabular}

Sumber : Data Primer (Diolah Tahun 2019)

Berdasarkan tabel 4.10 menunjukkan bahwa dari 318 orang responden yang memiliki sikap positif dan pelaksanaan thaharah baik berjumlah 108 responden (72,5\%). Berdasarkan hasil uji Chi-Square diketahui p value $=0,04$ dimana 0,04 $<$ dari 0,05 maka terdapat hubungan antara Sikap dengan pelaksanaan Thaharah pada remaja putri di Pasantren Babun Najah Banda Aceh.

3) Hubungan Usia Menarche dengan Pelaksanaan Thaharah

Tabel 4.11

Hubungan Usia Menarche dengan Pelaksanaan Thaharah Selama Menstruasi Pada Remaja Putri di Pasantren Babun Najah Banda Aceh

\begin{tabular}{|l|c|c|c|c|c|c|c|}
\hline \multirow{2}{*}{ Thaharah } & \multicolumn{4}{|c|}{ Usia Menarche } & \multicolumn{2}{|c|}{ Total } & \multirow{2}{*}{$\mathrm{p}$} \\
\cline { 2 - 8 } & $<\mathbf{1 0}$ & $\mathbf{\%}$ & $\mathbf{1 0}$ & $\mathbf{\%}$ & $\mathbf{n}$ & $\mathbf{\%}$ & \\
\hline Baik & 3 & 2 & 146 & 98 & 149 & 100 & \multirow{2}{*}{0.01} \\
\hline Kurang & 15 & 8.9 & 154 & 91.1 & 169 & 100 & \\
\hline
\end{tabular}

Sumber : Data Primer (Diolah Tahun 2019)

Berdasarkan tabel 4.11 menunjukkan bahwa dari 318 orang responden yang memiliki usia menarche $\geq 10$ dan pelaksanaan thaharah baik berjumlah 146 responden(98\%). Berdasarkan hasil uji Chi-Square diketahui $\mathrm{p}$ value $=0,01$ dimana $0,01<$ dari 0,05 maka 
Journal of Healthcare Technology and Medicine Vol. 5 No. 2 Oktober 2019

Universitas Ubudiyah Indonesia

e-ISSN : 2615-109X

terdapat hubungan antara usia menarche dengan pelaksanaan Thaharah pada remaja putri di Pasantren Babun Najah Banda Aceh.

\section{4) Hubungan Pendidikan Ibu dengan Pelaksanaan Thaharah}

Tabel 4.12

Hubungan Pendidikan Ibu dengan Pelaksanaan Thaharah Selama Menstruasi Pada Remaja Putri di Pasantren Babun Najah Banda Aceh

\begin{tabular}{|c|c|c|c|c|c|c|c|c|c|}
\hline \multirow[t]{3}{*}{ Thaharah } & \multicolumn{6}{|c|}{ Pendidikan Ibu } & \multirow{2}{*}{\multicolumn{2}{|c|}{ Total }} & \multirow[t]{3}{*}{$P$ value } \\
\hline & \multicolumn{2}{|c|}{ Dasar } & \multicolumn{2}{|c|}{ Menengah } & \multicolumn{2}{|c|}{ Tinggi } & & & \\
\hline & $\mathbf{f}$ & $\%$ & $\mathbf{f}$ & $\%$ & $\mathbf{f}$ & $\%$ & $\mathbf{f}$ & $\%$ & \\
\hline Baik & 21 & 14.1 & 74 & 49.6 & 54 & 36.3 & 149 & 100 & 0.02 \\
\hline Kurang & 43 & 25.4 & 65 & 38.4 & 61 & 36.2 & 169 & 100 & \\
\hline
\end{tabular}

Sumber : Data Primer (Diolah Tahun 2019)

Berdasarkan tabel 4.12 menunjukkan bahwa dari 318 orang responden yang pendidikan ibu menengah dan pelaksanaan thaharah baik berjumlah 74 responden $(49,6 \%)$. Berdasarkan hasil uji Chi-Square diketahui p value $=0,02$ dimana 0,02 < dari 0,05 maka terdapat hubungan antara pendidikan ibu dengan pelaksanaan Thaharah pada remaja putri di Pasantren Babun Najah Banda Aceh.

\section{5) Hubungan Dukungan Keluarga dengan Pelaksanaan Thaharah}

Tabel 4.13

Hubungan Dukungan Keluarga dengan Pelaksanaan Thaharah Selama Menstruasi Pada Remaja Putri di Pasantren Babun Najah Banda Aceh

\begin{tabular}{|l|c|c|c|c|c|c|c|}
\hline \multirow{2}{*}{ Thaharah } & \multicolumn{4}{|c|}{ Dukungan Keluarga } & \multicolumn{2}{c|}{ Total } & \multirow{2}{*}{ P } \\
\cline { 2 - 7 } & Tinggi & \% & Kurang & \% & n & \% & \multirow{2}{*}{0,02} \\
\hline Baik & 115 & 77,2 & 34 & 22.8 & 149 & 100 & \\
\hline Kurang & 110 & 65.1 & 59 & 34.9 & 169 & 100 & \\
\hline Total & 225 & 70.8 & 93 & 29.2 & 318 & 100 & \\
\hline
\end{tabular}

Sumber : Data Primer (Diolah Tahun 2019)

Berdasarkan tabel 4.13 menunjukkan bahwa dari 318 orang responden yang dukungan keluarga tinggi dan pelaksanaan thaharah baik berjumlah 115 responden $(77,2 \%)$. Berdasarkan hasil uji Chi-Square diketahui p value $=0,02$ dimana 0,02 $<$ dari 0,05 maka terdapat hubungan antara Dukungan Keluarga dengan pelaksanaan Thaharah pada remaja putri di Pasantren Babun Najah Banda Aceh. 
Journal of Healthcare Technology and Medicine Vol. 5 No. 2 Oktober 2019

Universitas Ubudiyah Indonesia

e-ISSN : 2615-109X

\section{Pembahasan}

a. Pelaksanaan Thaharah Selama Menstruasi Pada Remaja Putri di Pasantren Babun Najah Banda Aceh

Hasil penelitian menunjukkan bahwa dari 318 responden yang melaksanakan thaharah selama menstruasi 169 orang (53\%) berada pada kategori kurang. Hal ini menjelaskan bahwa remaja putri yang berada di Pasantren Babun Najah Banda Aceh masih belum mengerti bagaimana menjaga kebersihan tubuh selama menstruasi dengan baik dan benar sehingga para remaja ini beresiko mengalami penyakit infeksi dan jamur yang menyerang organ reproduksinya.

Penyebab infeksi pada organ reproduksi wanita pada saat menstruasi diantaranya dari bakteri, jamur yang dapat dengan mudah masuk kedalam Rahim melalui pembuluh darah jika tidak menjaga kebersihan tubuh misalnya menggunakan pembalut terus menerus, tidak mencuci tangan setelah buang air besar, tidak menggunting kuku)dan lingkungan, dengan benar. Salah satu gejala yang sering terjadi pada remaja yang mengalami infeksi pada alat reproduksi gatal dan keputihan. Penyebab terjadinya keputihan karena infeksi genetalia, adanya benda asing (alat kontrasepsi dalam rahim) penyakit kanker,stress dan perilaku personal hygiene yang kurang baik (Manuaba, 2009 dalam Devy dan Nazira, 2015).

Hasil penelitian menunjukkan dari 318 responden yang mengganti pembalut setiap 4 jam sekali berjumlah 182 (57,2\%) dan jumlah yang tidak mengganti pembalut setiap 4 jam berjumlah $136(42,7 \%)$ jumlah ini cukup besar mengingat salah satu penyebab terjadinya iritasi dan berkembangnya jamur pada organ kewanitaan karena pemakaian pembalut yang terlalu lama.

Selain itu remaja juga tidak menggunting kuku selama haid sebanyak 272 orang (85,5\%). Responden mengatakan tidak menggunting kuku selama menstruasi karena tidak diperbolehkan oleh ibu dan guru. Kuku yang panjang dapat mengakibatkan luka pada alat genetalia sehingga dapat menimbulkan terjadinya infeksi alat reproduksi. Kesehatan reproduksi remaja adalah suatu kondisi sehat yang menyangkut sistem, fungsi dan proses reproduksi yang dimiliki oleh remaja. Pengertian sehat disini tidak semata-mata berarti bebas dari kecacatan namun juga sehat secara mental serta sosial kultural ( IDAI, 2013). Kesehatan reproduksi remaja (KRR) merupakan bagian terpadu dari program kesehatan keluarga berencana di Indonesia. Program terpadu ini secara khusus bertujuan untuk mengatasi masalah terkait pernikahan dini, kehamilan tidak diinginkan, konsumsi tembakau dan alkohol serta HIV-AIDS ( Kemenkes, 2015). 
Journal of Healthcare Technology and Medicine Vol. 5 No. 2 Oktober 2019

Universitas Ubudiyah Indonesia

e-ISSN : 2615-109X

Pelaksanaan Thaharah yang kurang terjadi pada remaja putri di Pasantren Babun Najah Banda Aceh karena usia remaja putri yang berada di Pasantren Babun Najah Banda Aceh berada pada kategori remaja tengah, yaitu remaja yang berusia antara 1417 tahun sebanyak 161 (50,6\%). Usia seseorang mempengaruhi pengalaman seseorang dalam berperilaku atau bertindak, semakin matang usia seseorang perilaku kesehatan juga akan semakin membaik. Remaja tengah masih belum memahami dengan baik tentang pelaksanaan thaharah (personal hygiene) selama menstruasi sehingga perilaku thaharah (personal hygiene) kurang.

\section{b. Hubungan Pengetahuan dengan Pelaksanaan Thaharah Selama Menstruasi Pada Remaja Putri di Pasantren Babun Najah Banda Aceh}

Hasil penelitian menunjukkan bahwa dari 318 responden yang berpengetahuan rendah dan pelaksanaan thaharah kurang berjumlah 138 responden (76,9\%). Hasil uji Chi-Square diketahui $\mathrm{p}$ value $=0,038$ dimana $0,038<$ dari0,05 maka terdapat hubungan antara Pengetahuan dengan pelaksanaan Thaharah pada remaja putri di Pasantren Babun Najah Banda Aceh

Pengetahuan yang kurang tentang Pelaksanaan thaharah (personal hygiene) selama menstruasi disebabkan oleh remaja mendapatkan informasi tentang thaharah (personal hygiene) dari tenaga kesehatan hanya 38 responden $(11,9 \%)$ sehingga banyak responden yang tidak memahami tentang pelaksanaan thaharah yang benar selama menstruasi. Remaja yang tidak mengetahui tentang menggunakan handuk bergantian dengan teman dapat menyebabkan terjadi infeksi alat kelamin sebanyak 209 responden $65,7 \%$. Remaja yang tinggal diasrama selama masa pendidikan lebih sering menggunakan pakaian, handuk atau peralatan lainnya secara bergantian/bersama dengan temannya sehingga beresiko menderita penyakit infeksi kelamin. Penyakit infeksi kelamin dapat tertular melalui handuk dan pakain dalam yang digunakan bergantian dengan penderita. Selain itu dari 318 responden 139 (56,2\%) tidak mengetahui bahwa mencukur bulu kemaluan dilakukan paling lambat setiap 35 hari sekali. Manfaat mencukur bulu kemaluan akan membuat proses pembersihan produk kelenjar minyak dapat dilakukan dengan sempurna. Bila produk kelenjar ini tersisa di area rambut akan menyebabkan area tersebut menjadi lembab, sehingga bakteri akan mudah berkembang biak.

Pengetahuan yang kurang tentang pelaksanaan thaharah (personal hygiene) berhubungan dengan pelaksanaan thaharah yang kurang. Hasil penelitian ini sesuai dengan penelitian yang dilakukan oleh Ilmiawati dan Kuntoro (2016) pengetahuan yang 
Journal of Healthcare Technology and Medicine Vol. 5 No. 2 Oktober 2019

Universitas Ubudiyah Indonesia

e-ISSN : 2615-109X

dimiliki remaja putri berpengaruh terhadap kejadian keputihan. Pengetahuan yang dimiliki remaja putri mempengaruhi cara berpikir dan meningkatkan kesadaran menjaga kesehatan reproduksinya. Menurut Notoatmodjo (2012) Pengetahuan merupakan hasil dari tahu, dan ini terjadi setelah orang melakukan penginderaan terhadap suatu objek tertentu. Penginderaan terjadi melalui panca indra manusia, yakni indra penglihatan, pendengaran, penciuman, rasa dan raba. Sebagian besar pengetahuan manusia diperoleh melalui mata dan telinga. Pengetahuan atau ranah kognitif merupakan domain yang sangat penting dalam membentuk tindakan seseorang (overt behavior).

c. Hubungan Sikap dengan Pelaksanaan Thaharah Selama Menstruasi Pada Remaja Putri di Pasantren Babun Najah Banda Aceh

Hasil penelitian menunjukkan bahwa dari 318 orang responden yang memiliki sikap positif dan pelaksanaan thaharah baik berjumlah 108 responden (72,5\%). Hasil uji chi-Square diketahui $\mathrm{p}$ value $=0,04$ dimana $0,04<$ dari 0,05 maka terdapat hubungan antara Sikap dengan pelaksanaan Thaharah pada remaja putri di Pasantren Babun Najah Banda Aceh.

Remaja putri yang memiliki sikap positif dari 318 responden sebanyak 304 (95,5\%) sangat setuju terhadap pernyataan setiap remaja putri harus dapat menjaga kesehatan alat reproduksinya. Artinya setiap remaja merasa penting untuk menjaga alat reproduksinya sehingga tidak terjadi masalah dikemudian hari. Menjaga alat reproduksi harus dimulai dari remaja, yang dimulai dengan menjaga kebersihan diri (personal hygiene) selama menstruasi, karena pada saat ini rentan terjadi infeksi yang dapat berakibat terjadinya gangguan panggul dan infertilitas El-Ganiya \& E-fedewy 2005 dalam Gustina dan Djanah (2015). Penyebab terjadinya infeksi karena pada masa menstruasi rahim mengeluarkan lapisan endometrium sehingga pembuluh darah banyak yang membesar memudahkan bakteri dan kuman masuk kedalam tubuh . Hasil penelitian dari 318 responden $108(66 \%)$ bersikap positif terhadap pernyataan remaja perlu mengetahui alat-alat dan fungsi dari organ reproduksi dan serta saat menyentuh alat kelamin sebaiknya mencuci tangan terlebih dahulu dari 318 responden yang sangat setuju terhadap pernyataan tersebut sebanyak 198 responden (62,2\%). Menyentuh alat kelamin tanpa mencuci tangan terlebih dahulu merupakan salah satu penyebab masuknya kuman atau bakteri kedalam tubuh melalui alat kelamin. Sikap positif terhadap pernyataan tersebut dapat berdampak pada perilaku thaharah (personal hygiene) selama menstruasi pada remaja. 
Journal of Healthcare Technology and Medicine Vol. 5 No. 2 Oktober 2019

Universitas Ubudiyah Indonesia

e-ISSN : 2615-109X

Sikap adalah suatu bentuk evaluasi atau reaksi perasaan. Sikapseseorang terhadap suatu objek adalah perasaan berpihak (favourable) maupun perasaan tidak memihak (unfavourable) pada pernyataan atau objek tersebut. Sikap merupakan semacam kesiapan untuk beraksi terhadap suatu objek dengan cara-cara tertentu apabila individu dihadapkan pada suatu stimulus yang menghendaki adanya respons. Sikap positif akan cenderung mendorong seseorang berperilaku positif, Azwar (2011).

d. Hubungan Usia Menarche dengan Pelaksanaan Thaharah Selama Menstruasi Pada Remaja Putri di Pasantren Babun Najah Banda Aceh

Hasil penelitian menunjukkan bahwa dari 318 orang responden yang memiliki usia menarche $\geq 10$ dan pelaksanaan thaharah baik berjumlah 146 responden (98\%). Berdasarkan hasil uji Chi-Square diketahui p value $=0,01$ dimana 0,01 $<0,05$ maka terdapat hubungan antara usia menarche dengan pelaksanaan Thaharah pada remaja putri di Pasantren Babun Najah Banda Aceh.

Usia menarche remaja berkaitan dengan usia pertama kali seseorang mendapatkan menstruasi, semakin cepat seseorang menstruasi perilaku thaharah (personal hyigene) seharusnya semakin baik tetapi dalam penelitian ini semakin cepat seseorang mendapatkan menstruasi justru pelaksanaan thaharah personal hygiene semakin kurang baik 15 responden $(8,9 \%)$. Hal ini terjadi karena belum siap seseorang terhadap perubahan yang terjadi pada dirinya, sehingga remaja tersebut merasa malu terhadap perubahan tersebut. Dalam penelitian ini penilaian dilakukan pada remaja dan berapa lama remaja tersebut sudah mendapatkan menstruasi. Dari 318 responden 300 (98\%) remaja menarche $\geq 10$ tahun. Usia remaja di Pasantren Babun Najah berada pada remaja tengah dan akhir sebanyak 164 responden (51,5\%).

Hubungan usia menarche pada penelitian ini tidak sejalan dengan penelitian yang dilakukan oleh Bujawati dkk (2016) dari hasil analisi yang diperoleh bahwa tidak ada hubungan antara usia menarche dengan personal hygiene selama menstruasi dengan nilai $\mathrm{p}=0,473$. Hal ini menunjukkan bahwa usia menarche seseorang tidak dapat menentukan praktik hygiene menstruasinya. ${ }^{16}$

e. Hubungan Tingkat Pendidikan Ibu dengan Pelaksanaan Thaharah Selama

\section{Menstruasi Pada Remaja Putri di Pasantren Babun Najah Banda Aceh}

Hasil penelitian menunjukkan bahwa dari 318 orang responden yang pendidikan ibu menengah dan pelaksanaan thaharah baik berjumlah 74 responden $(49,6 \%)$. Berdasarkan hasil uji Chi-Square diketahui $\mathrm{p}$ value $=0,02$ dimana $0,02<$ dari 0,05 
Journal of Healthcare Technology and Medicine Vol. 5 No. 2 Oktober 2019

Universitas Ubudiyah Indonesia

e-ISSN : 2615-109X

maka terdapat hubungan antara pendidikan ibu dengan pelaksanaan Thaharah (personal hygiene) pada remaja putri di Pasantren Babun Najah Banda Aceh.

Pendidikan orang tua yang menengah dan tinggi dapat memberikan informasi pada anak tentang pelaksanaan thaharah (personal hygiene). Seseorang yang akan bertindak lebih rasional dan mudah menerima gagasan baru, Padila (2014). Green dalam Harahap (2016) menyatakan bahwa terdapat beberapa faktor yang dapat mempengaruhi, yaitu faktor predisposisi, faktor pemungkin, faktor penguat, pengetahuan, sikap dan fasilitas yang tersedia belum mampu menjamin perilaku seseorang untuk seperti yang diharapkan namun adanya pengalaman dan pengaruh dari luar, seperti pendidikan ibu akan mempengaruhi perilaku juga.

\section{f. Hubungan Dukungan Keluarga dengan Pelaksanaan Thaharah Selama Mentruasi Pada Remaja Putri di Pasantren Babun Najah Banda Aceh}

Hasil penelitian menunjukkan bahwa dari 318 orang responden yang dukungan keluarga tinggi dan pelaksanaan thaharah baik berjumlah 115 responden (77,2\%). Berdasarkan hasil uji Chi-Square diketahui $\mathrm{p}$ value $=0,02$ dimana 0,02 $<$ dari 0,05 maka terdapat hubungan antara Dukungan Keluarga dengan pelaksanaan Thaharah pada remaja putri di Pasantren Babun Najah Banda Aceh.

Berdasarkan hasil diatas menunjukkan bahwa dukungan keluarga yang tinggi mempengaruhi pelaksanaan thaharah baik pada remaja putri. Remaja yang mendapatkan dukungan keluarga yang tinggi merasa memiliki ikatan yang erat dengan keluarga, merasa diperhatikan dan mendapatkan dukungan dari keluarga, Kebutuhan saat menstruasi terpenuhi dan pergi kepetugas kesehatan juka mengalami masalah menstruasi salah satu bentuk dukungan yang diberikan keluarga pada remaja sat menstruasi

Hasil penelitian ini sejalan dengan penelitian yang dilakukan Suryani (2019) di SMP Negeri 12 Kota Pekan Baru tentang hubungan dukungan dengan perilaku personal hygiene pada saat menstruasi $\mathrm{p}$ value 0,000 dimana dari 43 responden yang mendapatkan dukungan untuk melakukan personal hygiene 13 diantaranya memiliki perilaku negatif tentang personal hygiene.

\section{KESIMPULAN}

Setelah melakukan penelitian terhadap 318 responden, maka peneliti dapat mengambil kesimpulan bahwa a) Pelaksanaan Thaharah (Personal Hygiene) pada remaja putri di Pasantren Babun Najah Banda Aceh berada pada kategori kurang sebanyak 169 responden (53\%). b) Ada hubungan antara Pengetahuan dengan pelaksanaan Thaharah pada 
Journal of Healthcare Technology and Medicine Vol. 5 No. 2 Oktober 2019

Universitas Ubudiyah Indonesia

e-ISSN : 2615-109X

remaja putri di Pasantren Babun Najah Banda Aceh dengan p value $(0,038)$. c)Ada hubungan antara Sikap dengan pelaksanaan Thaharah pada remaja putri di Pasantren Babun Najah Banda Aceh dengan p value $(0,04)$. d) Ada hubungan usia menarche dengan pelaksanaan Thaharah pada remaja putri di Pasantren Babun Najah Banda Aceh dengan p value $(0,01)$. e) Ada hubungan pendidikan ibu dengan pelaksanaan Thaharah pada remaja putri di Pasantren Babun Najah Banda Aceh dengan p value (0,02). f) Ada hubungan dukungan keluarga dengan pelaksanaan Thaharah pada remaja putri di Pasantren Babun Najah Banda Aceh dengan $\mathrm{p}$ value $(0,02)$.

\section{SARAN}

\section{Bagi Remaja}

Diharapkan remaja putri di pasantren Babun Najah Banda Aceh untuk meningkatkan pengetahuan tentang thaharah (personal hygiene) selama menstruasi sehingga jumlah remaja yang melaksanakan personal hygiene bertambah pada kategori baik

\section{Bagi Petugas Kesehatan}

Diharapkan bagi petugas kesehatan untuk meningkatkan pelayanan kesehatan dan memberikan informasi kepada masyarakat khususnya remaja tentang cara melaksanakan thaharah (personal hygiene) selama menstruasi.

\section{Bagi penelitian selanjutnya}

Diharapkan bagi peneliti selanjutnya untuk dapat menambah variabel penelitian dan membahas dengan multivariate.

\section{DAFTAR PUSTAKA}

1. Azwar S. 2011. Sikap Manusia: Teori dan Pengukurannya. Jakarta: Pustaka Pelajar

2. Badan Pusat Statistik Aceh.2016. https://aceh.bps.go.id/

3. Bujawati. E, Raodhah. S dan Indriyanti, 2017. Faktor-faktor Yang Berhubungan dengan Personal Hygiene Selama Menstruasi Pada Santriwati di Pasantren Babul Khaer Kabupaten Bulukumba, Procinsi Sulawesi Selatan Tahun 2016. Jurnal Higiene Vol. 3 No. 1

4. Depkes. 2012. Kesehatan Remaja. Jakarta. Salemba Medika

5. Devy, S. R. Dan Nazira. A. 2015. Pengaruh Personal Reference, Thought And Feeling Terhadap Kesehatan Reproduksi Santri Putri Pondok Pesantren X Jurnal Promosi Kesehatan The Indonesian Journal Of Health Promotion And Health Education VOL 3, NO, 2 https://ejournal.unair.ac.id/index.php/PROMKES/article/view/4470, di unggah september 2019

6. Dinkes Aceh. 2016. Profil Dinas Kesehatan Provinsi Aceh.

7. Eswi Abeer, Helal Houaida, and Elarousy Wafaa. 2012. Menstrual Attitude and Knowledge among Egyptian Female Adolescents. Journal of American Science, 8(6) 
Journal of Healthcare Technology and Medicine Vol. 5 No. 2 Oktober 2019

Universitas Ubudiyah Indonesia

e-ISSN : 2615-109X

8. Fitriyah, N, Indriani, D, Sulistyorini, Y. 2013. Riwayat Kesehatan Reproduksi Remaja., Jurnal Biometrika dan Kependudukan Volume 2 , Nomor 2. http://journal.unair.ac.id/downloadfull/BIOMETRIK6845-d2d40c7331fullabstract.pdf, diunggah 19 April 2019

9. Gustina E dan Djannah S.N 2015. Sumber Informasi dan Pengetahuan Tentang Menstrual Hygiene Pada Remaja Putri, Jurnal Kemas Vol 10 No 2 Universitas Negeri Semarang

10. Harahap. R. A 2016. Pengaruh faktor predisposing, enabling dan reinforcing terhadap pemberian imunisasi hepatitis $\mathrm{b}$ pada bayi Di puskesmas bagan batu kecamatan bagan Sinembah kabupaten rokan hilir jurnal Jumantik Vol. 1 No. 1 Nopember 2016

11. Hidayat, Syamsul. 2011. Serial Buku Pegangan Kuliah Al Islam Dan Kemuhammadiyahan. Surakarta. LPID

12. IDAI, 2013, Kesehatan Reproduksi Remaja Dalam Aspek Sosial, Indonesian Pediatric Society Committed in Improving The Health Of Indonesian Childrenhttp://www.idai.or.id/artikel/seputar-kesehatan-anak/kesehatan-reproduksiremaja-dalam-aspek-sosial

13. Ilmiawati dan Kuntoro. 2016. Pengetahuan Personal Hygiene Remaja Putri Pada Kasus Keputihan. Jurnal Biometrika dan Kependudukan, Vol 5, No 1 Juli 2016 diunggah 20 September 2019

14. Kementerian Kesehatan RI, 2015. Infodatin Pusat Data dan Informasi Kesehatan Reproduksi Remaja . Jakarta.

15. Manan, EL. 2011. Kamus Pintar Kesehatan Wanita. Jogjakarta. Buku Biru

16. Notatmodjoe, Soekidjo, 2012. Promosi Kesehatan dan Perilaku Kesehatan. Jakarta Rineka Cipta

17. Padila, 2014 Keperawatan Maternitas, Yogyakarta Nuha Medika

18. Priyitno, S. 2014. Buku Lengkap Kesehatan Organ Reproduksi Wanita. Jakarta Selatan: Saufa

19. Suryani. Linda 2019. Faktor-Faktor Yang Mempengaruhi Perilaku Remaja Putri Tentang Personal Hygiene Pada Saat Menstruasi di SMP Negeri 12 Kota Pekanbaru. Journal Of Midwifery Science Vol.3 No. 2 
. 